\title{
Validation of Lake Whitefish Catch-Per-Unit-Effort Data with Time Series Analysis
}

\author{
Kwang Ming Liu' and A. L. Jensen \\ School of Natural Resources. The University of Michigan \\ Ann Arbor, Michigan 48109-1105, USA
}

\begin{abstract}
Catch-per-unit-effort (CPUE) data for lake whitefish Coregonus clupeaformis in Michigan waters of Lake Huron were examined with time analysis to test if they can describe the abundance of lake whitefish. Relations between lake whitefish CPUE and environmental and biological data were investigated with cross-correlation analysis. A 4-year time lag, corresponding to the age at maturity, was found for lake whitefish CPUE. Cross-correlation analysis indicated that lake whitefish CPUE was negatively correlated with monthly air temperatures and abundance of sea lamprey Petromyzon marinus in previous years, and CPUE was positively correlated with fishing effort I year later. The results indicated that fishermen track lake whitefish abundance and that CPUE can describe fluctuations of the lake whitefish population.
\end{abstract}

Fisheries for lake whitefish Coregonus clupeaformis on the Great Lakes often have been assessed with catch statistics rather than with catchper-unit-effort (CPUE) statistics (e.g.. Berst and Spangler 1973; Christie 1973; Hartman 1973; Lawrie and Rahrer 1973; Wells and McLain 1973). Extensive effort data are available for the Great Lakes and CPUE data should be a better index of abundance than catch data because changes in effort and catchability produce different catches even when abundance does not change (e.g., Ricker 1975). However, CPUE data for the lake whitefish fisheries have been suspected of error because CPUE often increases as yield increases, whereas it should decrease if the fish are being fished up (e.g., Christie 1973). If changes in CPUE represent changes in lake whitefish abundance, then fishing effort tracks abundance of lake whitefish, and both yield and effort increase when abundance increases and decrease when abundance decreases. This would mean that the large fluctuations in catch and CPUE result from changes in abundance and not from fishing, and that conventional methods of stock assessment that are based on assumptions of constant recruitment or a carrying capacity are of no value for assessment of lake whitefish fisheries.

Abundance data on lake whitefish are not available, so it cannot be determined with certainty whether or not CPUE data reflect changes in abundance. We approached this problem indi-

\footnotetext{
I Present address: Department of Fisheries, National Taiwan Ocean University, 2 Pei-Ning Road, Keelung 20224, Taiwan, Republic of China.
}

rectly, seeking biologically meaningful patterns in the CPUE data that would reflect expected patterns in lake whitefish abundance.

We used time series and cross-correlation analyses for this purpose.

Time series analysis has been applied to several fisheries (Jensen 1976; Van Winkle et al. 1979; Saila et al. 1980; Stocker and Hilborn 1981; Roff 1983; Jensen 1985; Stone and Cohen 1990), and biologically meaningful time lags have been found for marine species (Jensen 1985). The two general approaches to time series analysis are based on frequency domain or time domain. The frequency domain (spectral analysis) model decomposes a data series into sine and cosine functions. Spectral analysis is particularly useful when a series is thought to arise from a relatively small set of cyclical functions. Time domain (autoregressive and moving-average) models treat a series as a function of previous values in the same series; these models seem more appropriate for population analyses because they require few assumptions about the underlying model and they can fit complex time series with few parameters (Moran 1953). Outputs from autoregressive models can be explained in terms of biological phenomena such as reproductive time lags, but moving-average terms are not easily interpreted and a moving-average process can always be written as an autoregressive process. Therefore, only autoregressive terms are used in this study.

\section{Data Sources}

The catch and effort data for lake whitefish were from Jensen and Buettner (1976), Anonymous (1989a), and U.S. Fish and Wildlife Service (un- 


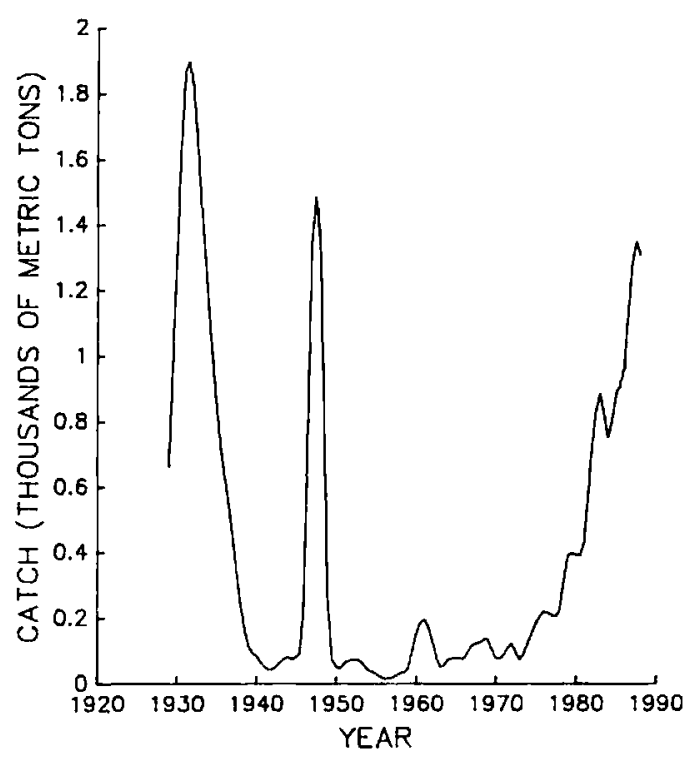

FIGURE 1.-Observed catch series (1929-1988) for lake whitefish in Michigan waters of Lake Huron.

published data); the data were consistent for 60 years (1929-1988). Catch data were changed from pounds into kilograms, and kilograms per trapnet lift was used as the standard CPUE. The CPUE was calculated as (Gulland 1969)

$$
\text { CPUE }=\left(C_{g}+C_{t}\right) /\left\{E_{t}+\left[C_{g} /\left(C_{t} / E_{t}\right)\right]\right\}
$$

$C_{t}=$ trap-net catch of lake whitefish (kg);

$C_{g}=$ gill-net catch of lake whitefish $(\mathrm{kg})$;

$E_{t}=$ trap-net effort (lift).

Monthly air temperature data were provided by the National Oceanic and Atmospheric Administration (NOAA) Great Lakes Environmental Research Laboratory in Ann Arbor and were available from 1929 to 1988. Data (1947-1988) for sea lamprey Petromyzon marinus were from Smith and Tibbles (1980) and Anonymous (1989b). Model parameters were estimated with the SERIES procedure in the statistical package SYSTAT (Wilkinson 1988).

\section{Results and Discussion}

Commercial production of lake whitefish in Michigan waters of Lake Huron varied from 1,877 tonnes in the early 1930s to less than 20 tonnes in the $1950 \mathrm{~s}$, and it recovered to 1,300 tonnes in 1988 (Figure 1). Before 1978, the bulk of the lake whitefish landings came from state-licensed trapnet and large-mesh gill-net fisheries (Rakoczy 1984). Thereafter, a tribal gill-net fishery shared the resource and tribal catch rapidly increased from

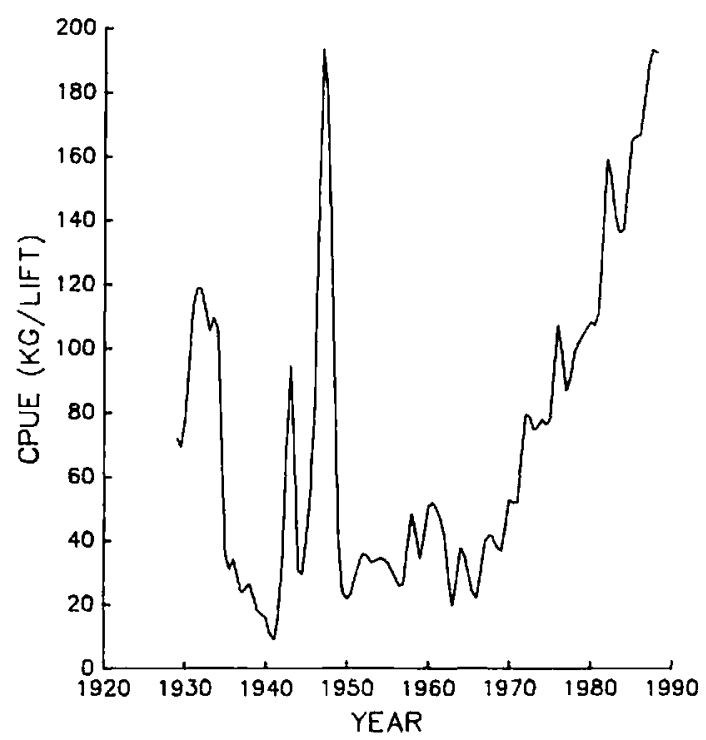

FIGURE 2.-Observed catch-per-unit-effort (CPUE) series (1929-1988) for lake whitefish.

$7 \%$ of lake whitefish landings in 1980 to $58 \%$ in 1988. The remainder of the lake whitefish catch was from a state-licensed trap-net fishery. The lake whitefish CPUE series follows a pattern similar to that of catch ( $r=0.72$, Figure 2$)$, and catch is related to effort $(r=0.67)$. The CPUE data were subjected to autocorrelation analysis to determine if biologically meaningful time lags could be detected. The CPUE series of lake whitefish was not stationary (Figure 2), but the twice-differenced series appeared to be nearly stationary with a constant mean but with a somewhat higher variance between 1942 and 1952 (Figure 3). Further differencing did not improve consistency of the series. The partial autocorrelation function for the

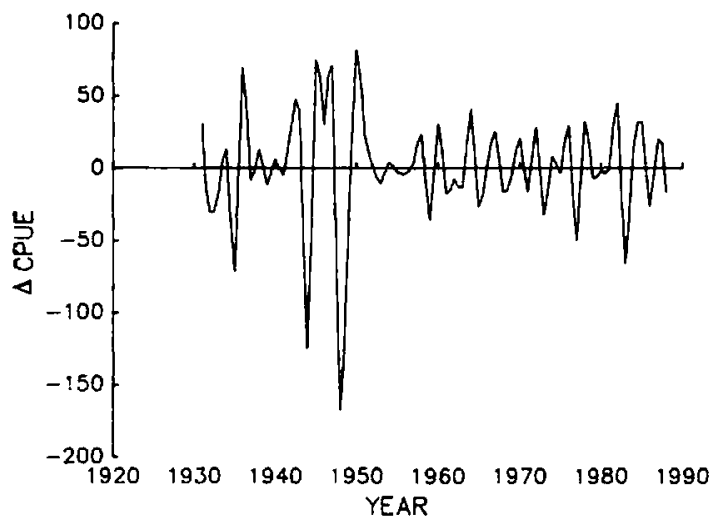

FIGURE 3.-Second difference of the catch-per-uniteffort (CPUE) series for lake whitefish. 


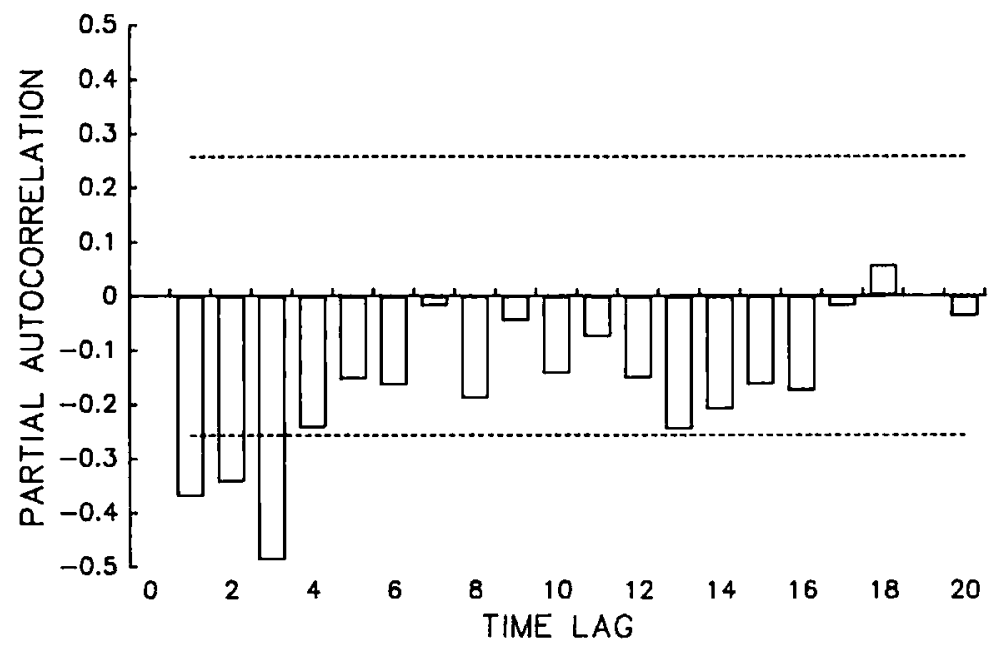

FIGURE 4. - Partial autocorrelations for twice-differenced catch-per-unit-effort (CPUE) series for lake whitefish. Time lag is in years. Dashed lines delimit $95 \%$ confidence intervals.

twice-differenced CPUE series indicated negative relations at lags of 1,2 , and 3 years, suggesting a 4-year time lag in CPUE (Figure 4). This result is important, because lake whitefish mature at age 4. A 4-year time lag corresponds to a delayed density dependence for age at maturity, and it indicates that abundance of lake whitefish was negatively correlated with abundance 4 years earlier. Abundant lake whitefish cohorts tended to produce smaller cohorts.

To evaluate the fit of the autoregressive model

$$
\begin{aligned}
U_{t}= & 1.332 U_{t-1}-0.251 U_{t-2} \\
& +0.506 U_{t-3}-0.587 U_{t-4}
\end{aligned}
$$

we used the model for year-ahead forecasts of lake whitefish CPUE, $U$, being the forecast of yearahead CPUE. The 1-year-ahead forecast of CPUE explains $42 \%$ of the total variance for CPUE and there were no significant time lags in the residuals (Figure 5).

To describe the relation between CPUE and environmental variables, cross-correlation analysis was applied to the CPUE and monthly average air temperature data. Climatic factors affect growth of lake whitefish (Reckahn 1986; Taylor et al. 1986), and many authors have proposed that yearclass strength of lake whitefish is influenced by climatic influences on egg and fry stages (Van Oos-

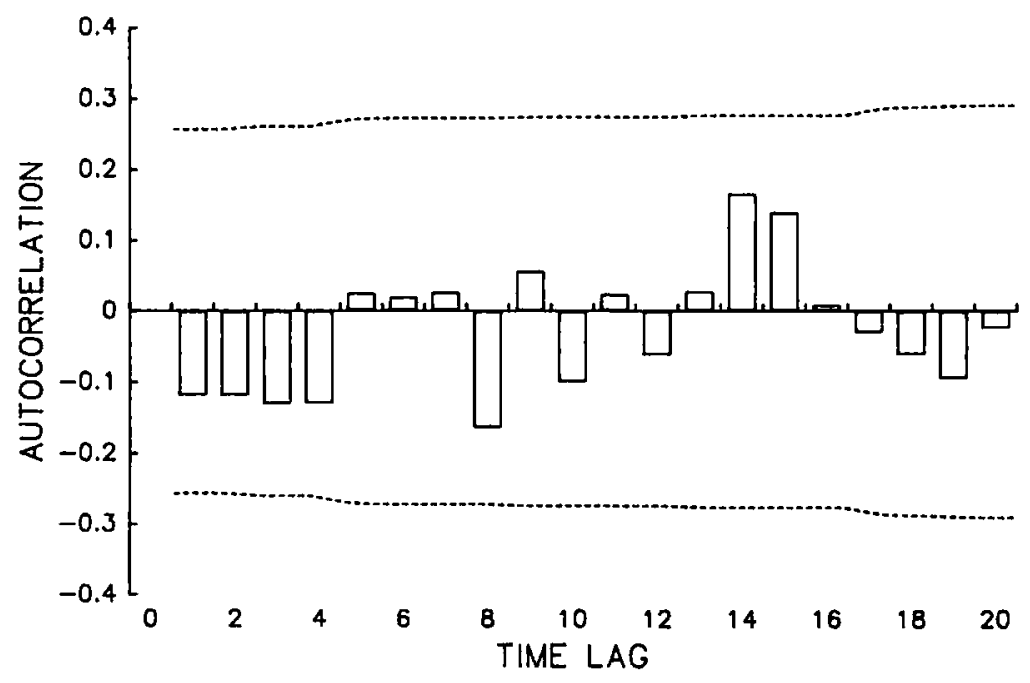

FIGURE 5.-Autocorrelations of residuals of the forecasting equation of the catch-per-unit-effort (CPUE) series for lake whitefish. Time lag is in years. Dashed lines delimit $95 \%$ confidence intervals. 
TABLE 1. - Significant ( $P \leq 0.05$ ) coefficients of crosscorrelation models for lake whitefish catch per unit effort and catch, effort, monthly air temperatures (January and March), and sea lamprey abundance. Coefficients for all other months are not significant.

\begin{tabular}{|c|c|c|c|c|c|}
\hline \multirow[b]{2}{*}{$\underset{\text { (ycars) }}{\text { Lag }}$} & \multicolumn{5}{|c|}{ Coefficient of cross-correlation } \\
\hline & Catch & Effort & January & March & $\begin{array}{c}\text { Sea } \\
\text { lamprcy }\end{array}$ \\
\hline-7 & & & -0.34 & & \\
\hline-6 & & & -0.37 & & \\
\hline-5 & & & -0.35 & & -0.29 \\
\hline-4 & & & -0.33 & & -0.30 \\
\hline-3 & & & -0.31 & & -0.32 \\
\hline-2 & & & -0.29 & -0.30 & -0.34 \\
\hline-1 & & & & -0.32 & -0.29 \\
\hline 0 & 0.71 & & & & \\
\hline 1 & 0.37 & 0.47 & & & \\
\hline
\end{tabular}

ten 1942; Miller 1952; Christie 1963; Lawler 1965; Freeberg et al. 1990). Miller (1952) concluded that year-class strength might be inversely correlated with strength of winds. Lawler (1965) suggested that temperature is more important than other climatic factors in determining the year-class strength of lake whitefish in Lake Erie. Lawler found that embryonic development of lake whitefish is restricted to a narrow range of temperatures, the optimum for development being close to $0.5^{\circ} \mathrm{C}$, and that lake whitefish are limited to waters where temperatures stay close to the freezing point during development and hatching. Taylor et al. (1986) proposed that severity of winter (indexed by ice cover) and spring temperature influence year-class strength more than the stock-recruitment relation. Freeberg et al. (1990) concluded that yearclass strength is detcrmined by the timing of ice cover, an early cold winter producing the highest survival, and by the highest food availability during the first 7 weeks of life.

We found significant cross-correlations between CPUE and monthly average air temperatures (January and March) in past years (Table 1). These cross-correlations suggest a negative relation between CPUE for lake whitefish and January temperatures in the past $1-5$ years, and a negative relation between CPUE and March temperatures in previous years. These analyses indicate that abundance of lake whitefish cohorts was associated with cold January and March temperatures during the early years of cohort life. This result is consistent with the results of others. especially of Taylor et al. (1986), who proposed that severity of winter and spring temperatures are the strongest determinants of year-class strength.

The relation between CPUE and the sea lam- prey index of abundance also was examined with cross-correlation analysis. The sea lamprey was an important factor in the decline of lake whitefish populations (Spangler 1970; Walter and Hoagman 1971). The lake whitefish fishery declined to its lowest level after the sea lamprey appeared in Lake Huron in the 1950s; after the sea lamprey was controlled in the 1960 s, the lake whitefish population gradually recovered (Figure 1). Significant negative cross-correlations were found between lake whitefish CPUE and sea lamprey abundance at lags of $1,2,3,4$, and 5 years, suggesting that the abundance of lake whitefish was associated with the abundance of sea lamprey 1-5 years earlier. This indicates that the effect of sea lamprey abundance was both through direct mortality and through a reduced recruitment that may have resulted from a smaller stock size of lake whitefish.

Finally, the relations between the catch and effort series, the catch and CPUE series, and the effort and CPUE series were examined with crosscorrelation analysis. Significant positive crosscorrelations between catch and effort were found at forward lags of 0 and 1 year, indicating that catch of lake whitefish was associated with effort in the present year and 1 year later. Significant positive cross-correlations between catch and CPUE and between effort and CPUE were also found at forward lags of 0 and 1 year and 1 year. respectively (Table 1). These results, combined with the results showing that lake whitefish abundance fluctuated with environmental factors and with sea lamprey abundance, indicate that fishermen track the abundance of lake whitefish and that effort increased when abundance increased. We conclude that CPUE describes fluctuations of the lake whitefish abundance, although fishing patterns, weather, catchability, and other factors might affect CPUE.

\section{Acknowledgments}

We thank R. A. Assel of the NOAA Great Lakes Environmental Research Laboratory in Ann Arbor, Michigan, and G. Fleischer of the U.S. Fish and Wildlife Service's Great Lakes Fishery Laboratory in Ann Arbor for their kindness in providing us environmental and catch and effort data.

\section{References}

Anonymous. 1989a. Commercial fish productionpounds and values. U.S. Fish and Wildlife Service, Great Lakes Fishery Laboratory, Ann Arbor. Michigan.

Anonymous. 1989b. Status of the fishery resource. An 
assessment of major fish stocks in treaty-ceded waters of the upper Great Lakes: state of Michigan. U.S. Fish and Wildlife Service, Great Lakes Fishery Laboratory, Ann Arbor, Michigan.

Berst, A. H., and G. R. Spangler. 1973. Lake Huron: the ecology of the fish community and man's effects on it. Great Lakes Fishery Commission Technical Report 21.

Christie, W. J. 1963. Effects of artificial propagation and the weather on recruitment in the Lake Ontario whitefish fishery. Journal of the Fisheries Research Board of Canada 20:597-646.

Christie, W. J. 1973. A review of the changes in the fish species composition of Lake Ontario. Great Lakes Fishery Commission Technical Report 13.

Freeberg, M. H., W. W. Taylor, and R. W. Brown. 1990. Effect of egg and larval survival on year-class strength of lake whitefish in Grand Traverse Bay, Lake Michigan. Transactions of the American Fisheries Society 119:92-100.

Gulland, J. A. 1969. Manual of methods for fish stock assessment, part 1. Fish population analysis. FAO (Fish and Agriculture Organization of the United Nations) Manuals in Fisheries Science 4, FRS/M4.

Hartman, W. L. 1973. Effects of exploitation, environmental changes, and new species on the fish habitats and resources of Lake Erie. Great Lakes Fishery Commission Technical Report 22.

Jensen, A. L. 1976. Time series analysis and forecasting of Atlantic menhaden catch. Chesapeake Science 17:305-307.

Jensen, A. L. 1985. Time series analysis and the forecasting of menhaden catch and CPUE. North American Journal of Fisheries Management 5:78-85.

Jensen, A. L., and H. J. Buettner. 1976. Lake trout, lake whitefish, chubs, and lake herring yield and effort data for state of Michigan waters of the upper Great Lakes: 1929-1973. University of Michigan, Michigan Sea Grant Program, Technical Report 52, Ann Arbor.

Lawler, G. H. 1965. Fluctuations in the success of yearclasses of whitefish populations with special reference to Lake Erie. Journal of the Fisheries Research Board of Canada 22:1197-1226.

Lawrie, A. H., and J. R. Rahrer. 1973. Lake Superior: a case history of the lake and its fisheries. Great Lakes Fishery Commission Technical Report 19.

Miller, R. B. 1952. The relative strengths of whitefish year class as affected by egg plantings and weather. Journal of Wildlife Management 16:39-50.

Moran, P. A. P. 1953. The statistical analysis of the Canadian lynx cycles. I. Structure and prediction. Australian Journal of Zoology 1:163-173.

Rakoczy, G. P. 1984. Vital statistics and estimated optimum harvest levels of six stocks of lake whitefish from Michigan waters of Lake Huron. Michigan Department of Natural Resources, Fishery Division, Fishery Research Report, Lansing.
Reckahn, J. A. 1986. Long-term cyclical trends in growth of lake whitefish in South Bay, Lake Michigan. Transactions of the American Fisheries Society 115:787-804.

Ricker, W. E. 1975. Computation and interpretation of biological statistics of fish populations. Fisheries Research Board of Canada Bulletin 191.

Roff, D. A. 1983. Analysis of catch/effort data: a comparison of three methods. Canadian Joumal of Fisheries and Aquatic Sciences 40:1496-1 506.

Saila, S. B., M. Wigbout, and R. J. Lermit. 1980. Comparison of some time series models for the analysis of fisheries data. Journal du Conseil Permanent International pour l'Exploration de la Mer 39:44-52.

Smith, B. R., and J. J. Tibbles. 1980. Sea lamprey (Petromyzon marinus) in Lakes Huron, Michigan, and Superior: history of invasion and control, 193678. Canadian Journal of Fisheries and Aquatic Sciences 37:1780-1801.

Spangler, G. R. 1970. Factors of mortality in an exploited population of whitefish, Coregonus clupeaformis, in northern Lake Huron. Pages 515-529 in C. C. Lindsey and C. S. Woods, editors. Biology of coregonid fishes. University of Manitoba Press, Winnipeg.

Stocker, M., and R. Hilborn. 1981. Short-term forecasting in marine fish stocks. Canadian Journal of Fisheries and Aquatic Sciences 38:1247-1 254.

Stone, J. N., and Y. Cohen. 1990. Changes in species interactions of the Lake Superior fisheries system after the control of sea lamprey as indicated by time series models. Canadian Journal of Fisheries and Aquatic Sciences 47:251-261.

Taylor, W. W., M. A. Smale, and M. H. Freeberg. 1986. Biotic and abiotic determinants of lake whitefish (Coregonus clupeaformis) recruitment in northeastem Lake Michigan. Canadian Journal of Fisheries and Aquatic Sciences 44(Supplement 2):313-323.

Van Oosten, J. 1942. Relationship between the plantings of fry and production of whitefish in Lake Erie. Transactions of the American Fisheries Society 71: 118-121.

Van Winkle, W., B. L. Kirk, and B. W. Rust. 1979. Periodicities in Atlantic coast striped bass (Morone saxatilis) commercial fisheries data. Journal of the Fisheries Research Board of Canada 36:54-62.

Walter, G., and W. J. Hoagman. 1971. Mathematical models for estimating changes in fish populations with applications to Green Bay. Proceedings Conference on Great Lakes Research 14:170-184.

Wells, L., and A. L. McLain. 1973. Lake Michigan: man's effects on native fish stocks and other biota. Great Lakes Fishery Commission Technical Report 20.

Wilkinson, L. 1988. SYSTAT: the system for statistics. SYSTAT, Evanston, Illinois.

Received May 20. 1991 Accepted April 9, 1992 